\title{
Different Subtypes of Influenza Viruses Target Different Human Proteins and Pathways Leading to Different Pathogenic Phenotypes
}

\author{
Yujie Wang, ${ }^{1,2}$ Ting Song $\mathbb{D}^{1},{ }^{1}$ Kaiwu Li, ${ }^{1}$ Yuan Jin, ${ }^{1}$ Junjie Yue $\mathbb{D}^{1},{ }^{1}$ Hongguang Ren $\mathbb{D},{ }^{1}$ \\ and Long Liang (iD ${ }^{1}$
}

${ }^{1}$ State Key Laboratory of Pathogen and Biosecurity, Beijing Institute of Biotechnology, Beijing 100071, China
${ }^{2}$ Institute of Physical Science and Information Technology, Anhui University, Hefei, Anhui 230601, China

Correspondence should be addressed to Junjie Yue; yue_junjie@126.com, Hongguang Ren; bioren@163.com and Long Liang; ll@bmi.ac.cn

Received 25 April 2019; Accepted 17 July 2019; Published 22 October 2019

Academic Editor: Mingtao Zeng

Copyright (C) 2019 Yujie Wang et al. This is an open access article distributed under the Creative Commons Attribution License, which permits unrestricted use, distribution, and reproduction in any medium, provided the original work is properly cited.

\begin{abstract}
Different subtypes of influenza A viruses (IAVs) cause different pathogenic phenotypes after infecting human bodies. Analysis of the interactions between viral proteins and the host proteins may provide insights into the pathogenic mechanisms of the virus. In this paper, we found that the same proteins (nucleoprotein and neuraminidase) of H1N1 and H5N1 have different impacts on the NF- $\kappa$ B activation. By further examining the virus-host protein-protein interactions, we found that both NP and NA proteins of the $\mathrm{H} 1 \mathrm{~N} 1$ and $\mathrm{H} 5 \mathrm{~N} 1$ viruses target different host proteins. These results indicate that different subtypes of influenza viruses target different human proteins and pathways leading to different pathogenic phenotypes.
\end{abstract}

\section{Introduction}

Influenza A virus (IAV) belongs to the Orthomyxoviridae family. Its genome consists of eight segmented, negative-strand RNAs [1-3]. IAVs are further typed into many different subtypes based on the antigenicity of hemagglutinin (HA) and the neuraminidase (NA) [4], the proteins on the surface of the virus. Currently, $18 \mathrm{HA}(\mathrm{H} 1-\mathrm{H} 18)$ and $11 \mathrm{NA}(\mathrm{N} 1-\mathrm{N} 11)$ subtypes have been identified in IAVs [5]. Different subtypes of IAVs may have evolved various mechanisms to co-opt host processes and suppress host defenses, inducing different infectious phenotypic outcomes. For example, the highly transmissible seasonal H1N1 virus usually causes mild illness, while the highly pathogenic avian H5N1 virus often leads to severe cases when infecting humans. The pathogenic mechanism under this phenomenon needs more research efforts to reveal.

The innate immune system of human plays an important role in the hosts' resistance to viruses. The NF- $\kappa \mathrm{B}$ signaling pathway [6-9] is a key component of the innate immune system during its antiviral process. In mammals, there are two major NF- $\kappa$ B signaling pathways: the canonical NF- $\kappa$ B pathway and the noncanonical NF- $\kappa$ B pathway $[10,11]$. Under the stimulation of pathogenic microbial infections or their induced inflammatory factors, NF- $\kappa \mathrm{B}$ is normally activated by classical signaling pathways [12]. Diverse bacterial and viral pathogens target NF- $\kappa \mathrm{B}$ signaling pathway to evade host immune defenses. Some viruses suppress NF- $\kappa \mathrm{B}$ activation to dampen the host immune responses to maintain latency [13]. For example, human bocavirus (HBoV) proteins NS1 and NS1-70 [14], the mumps virus $(\mathrm{MuV})$ small hydrophobic protein $(\mathrm{SH})$ [15], and molluscum contagiosum virus (MCV) protein MC005 [16] inhibit TNF- $\alpha$-mediated activation of NF- $\kappa$ B by reducing the phosphorylation of $\mathrm{IKK} \beta, \mathrm{I} \kappa \mathrm{B} \alpha$, and $\mathrm{p} 65$ as well as the translocation of p65 into the nucleus. Some pathogenic microorganisms activate NF- $\kappa$ B for viral gene expression, replication and spread. For example, the K15 protein of KSHV and the early protein Nef of most primate lentiviruses enhances NF- $\kappa B$ activation to initiate proviral transcription $[17,18]$. IAVs can also interfere with antiviral responses by regulating the NF- $\kappa$ B signaling pathway. Studies have shown that influenza virus proteins interact with NF- $\kappa$ B to promote viral replication. For example, the IAV NS1 protein specifically inhibits 
IKK-mediated NF- $\kappa$ B activation and production of the NF- $\kappa \mathrm{B}$ induced antiviral genes by physically interacting with IKK through the C-terminal effector domain [19].

In this paper, we used the luciferase assay and the co-immunoprecipitation experiment to study how the NP and NA viral proteins of both HIN 1 and $\mathrm{H} 5 \mathrm{~N} 1$ interact with NF- $\kappa \mathrm{B}$ signaling pathway. We found that the H1N1 NP has little impact on the TNF- $\alpha$-induced NF- $\kappa \mathrm{B}$ transcriptional activation, while the H5N1 NP inhibits the TNF- $\alpha$-induced NF- $\kappa \mathrm{B}$ transcriptional activation by interacting with IKK $\alpha$. Furthermore, the H5N1 NP protein promotes the expression of $\mathrm{I} \kappa \mathrm{B} \alpha$ proteins, meanwhile, suppresses the phosphorylation of $\mathrm{I} \kappa \mathrm{B} \alpha$, and restrains the translocation of p65 into the nucleus of infected $293 \mathrm{~T}$ cells. We also found that the H5N1 NA activates the IL- $1 \beta$-induced $\mathrm{NF}-\kappa \mathrm{B}$ transcriptional activation through TAB2, while H1N1 NA inhibits the IL- $1 \beta$-induced $\mathrm{NF}-\kappa \mathrm{B}$ transcriptional activation by coimmunoprecipitating with IKK $\beta$. All these results imply divergent pathogenic mechanisms of different subtypes of IAVs.

\section{Materials and Methods}

2.1. Cell Culture and Transfection. 293 T (human embryonic kidney) and HeLa cells were cultured in Dulbecco's modified Eagle's medium (DMEM, Gibco) supplemented with $10 \%$ heat-inactivated fetal bovine serum (FBS, Gibco), $2 \mathrm{mM}$ L-glutamine, $100 \mathrm{U} / \mathrm{mL}$ penicillin, and $100 \mathrm{mg} /$ $\mathrm{mL}$ streptomycin. Transient transfections were performed with Lipofectamine 2000 (Invitrogen) according to the manufacturer's instructions.

2.2. Antibodies, Reagents. Anti-Flag (Sigma-Aldrich), anti-Myc (Santa Cruz), anti- $\alpha$-tubulin (Sigma-Aldrich), and anti-HA (Origene) mouse monoclonal antibodies were used as primary antibodies for immunoblotting and immunoprecipitation. HRP-conjugated goat anti-mouse IgG (ZSGB-BIO) antibodies were used as secondary antibodies for immunoblotting.

2.3. Immunoprecipitation, and Immunoblotting. Immunoprecipitation was performed using IP buffer (1\% Nonidet $\mathrm{P}-40,50 \mathrm{mM}$ Tris-HCl [pH 7.5], $150 \mathrm{mM} \mathrm{NaCl}$, and Complete $^{\mathrm{TM}}$ protease inhibitor cocktail-EDTA (Roche)). Whole cell extracts were prepared after transfection and incubated with indicated antibodies together with Protein A/G beads (Roche) overnight. Beads were then washed 4 times with IP buffer, and immunoprecipitates were eluted with SDS loading buffer (TransGen Biotech) and resolved in SDSPAGE gels. The proteins were transferred to PVDF membrane (Bio-Rad) and further incubated with the indicated antibodies. The antigen-antibody complexes were visualized by the Immobilon ${ }^{\mathrm{TM}}$ chemiluminescent detection kit (Millipore).

2.4. Dual-Luciferase Activity Assay. 293T (human embryonic kidney) cells were seeded in 24 -well plates $\left(1 \times 10^{5}\right.$ per well). 293T (human embryonic kidney) cells were transfected with empty vector, $50 \mathrm{ng}, 100 \mathrm{ng}, 150 \mathrm{ng}$ H5N1 NP or H1N1 NP expression plasmid, along with $125 \mathrm{ng}$ pNF- $\kappa$ B-luc, $25 \mathrm{ng}$ $\mathrm{pRL}-\mathrm{TK}$ utilizing transfection reagent (Invitrogen). After 24hour transfection, luciferase activity was measured through the dual-luciferase assay system (Promega) in accordance with the manufacturer's instructions.

2.5. Immunofluorescence Analysis. HeLa cells cultured on coverslips were fixed in $4 \%$ paraformaldehyde for $10 \mathrm{~min}$ and washed with PBS for three times. After that, cells were fixed with $0.1 \%$ Triton X-100 on ice for $5 \mathrm{~min}$, washed in PBS, and blocked in 1\% BSA for $20 \mathrm{~min}$. The coverslips were incubated with $1 \%$ BSA containing primary antibodies for $1 \mathrm{~h}$, followed by PBS wash for three times. The cells were further stained with Alexa Fluor ${ }^{\circledast}$ conjugated secondary antibodies (Abcam). Images were acquired on an Olympus FV1000 fluorescence microscope.

2.6. Statistical Analysis. Analyses were done with the statistical software SAS/STAT. Data analysis over time was undertaken by repeated-measures analysis with SAS/STAT. Differences were considered statistically significant if the $P$ value was $<0.05$.

\section{Results}

3.1. H5N1 NP and H1N1 NP Have Different Impacts on the TNF- $\alpha$-Induced NF- $\kappa B$ Activation. The nucleoprotein of negative-strand RNA viruses forms a major component of the ribonucleoprotein complex that is responsible for viral transcription and replication, and NP proteins of IAV support the progress of the polymerase during the elongation phase [20].

The dual-luciferase activity assay was performed to determine the impacts of the NP proteins from different subtypes of IAVs on the TNF- $\alpha$-induced NF- $\kappa$ B activation. The results showed that the H5N1 NP clone significantly inhibited TNF- $\alpha$ stimulated NF- $\kappa$ B promoter activity, while the H1N1 NP had little impact on it (Figures 1(a) and 1(b)).

It is known that activated NF- $\kappa \mathrm{B}$ signaling pathway can phosphorylate $\mathrm{I} \kappa \mathrm{B} \alpha$ and cause subsequent degradation [21]. To further verify the impact of the NP proteins on the NF- $\kappa \mathrm{B}$ signaling pathway, we examined the phosphorylation and degradation of $\mathrm{I} \kappa \mathrm{B} \alpha$ in the NF- $\kappa \mathrm{B}$ signaling pathway by immunoblotting. When treated with TNF- $\alpha$, the decreasing amount of $\mathrm{I} \kappa \mathrm{B} \alpha$ in $\mathrm{H} 5 \mathrm{~N} 1 \mathrm{NP}$-expressing cells was less than that in empty vector-transfected cells (Figure 1(c)). Furthermore, the level of phosphor-I $\kappa \mathrm{B} \alpha$ in the H5N1 NP-expressing cells was diminished (Figure $1(\mathrm{~d})$ ). The decreasing amount of $\mathrm{I} \kappa \mathrm{B} \alpha$ in the H1N1 NP-expressing cells was similar to that in the empty vector-transfected cells, which were both treated with TNF- $\alpha$ (Figure 1(e)). The level of phosphor-I $\kappa \mathrm{B} \alpha$ in the $\mathrm{H} 1 \mathrm{~N} 1$ NP-expressing cells was similar to the empty vector-transfected cells (Figure 1(f)). These results demonstrated that H5N1 NP protein suppressed TNF- $\alpha$-mediated I $\kappa \mathrm{B} \alpha$ phosphorylation and degradation while H1N1 NP protein had little impact on them. 


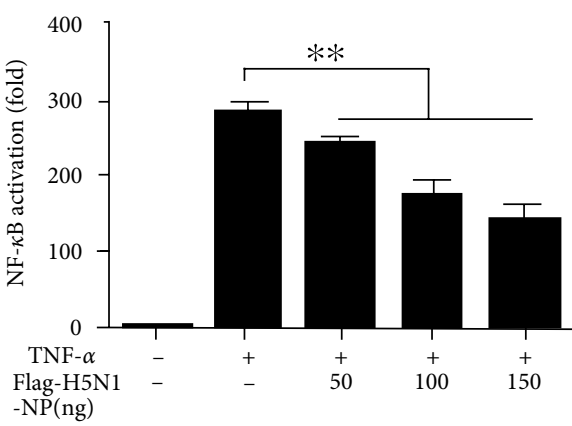

(a)

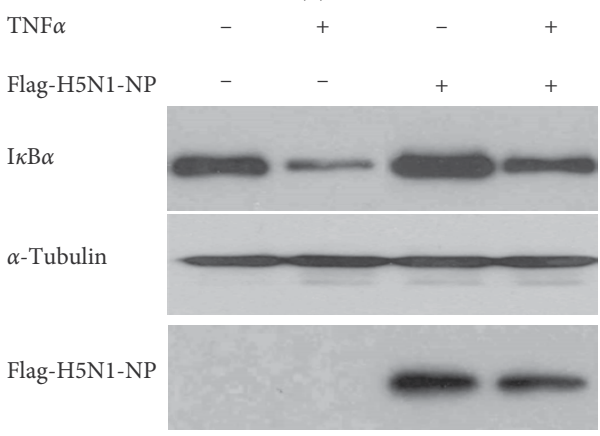

(c)

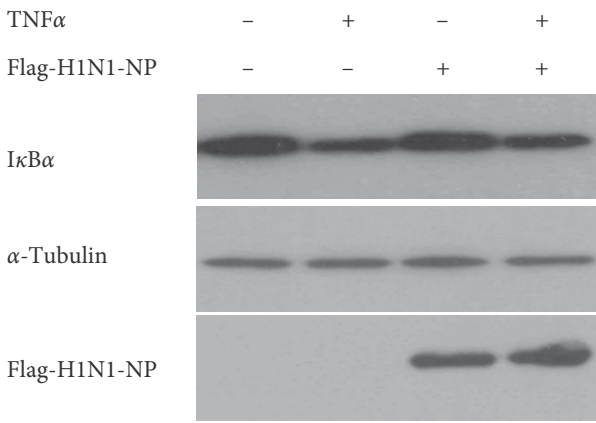

(e)

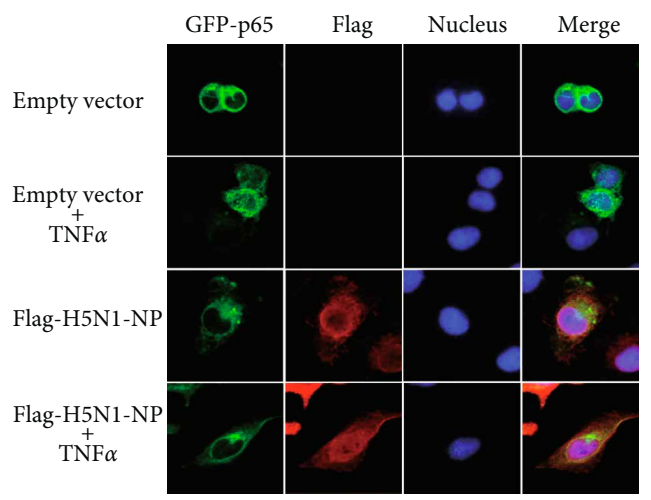

(g)

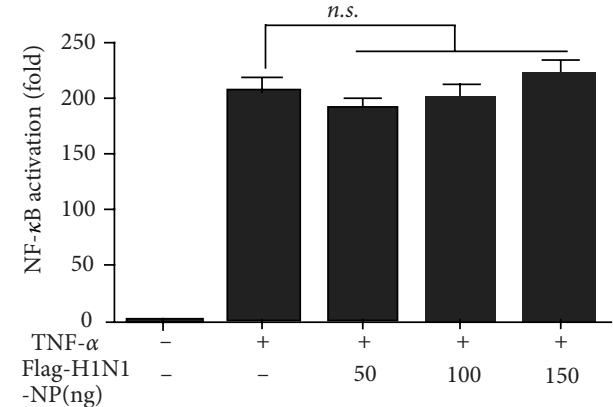

(b)

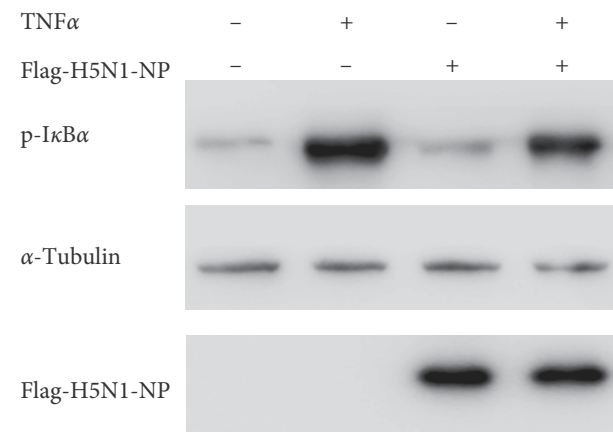

(d)

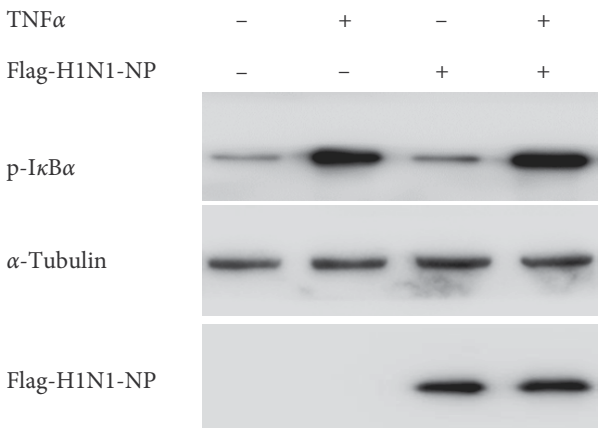

(f)

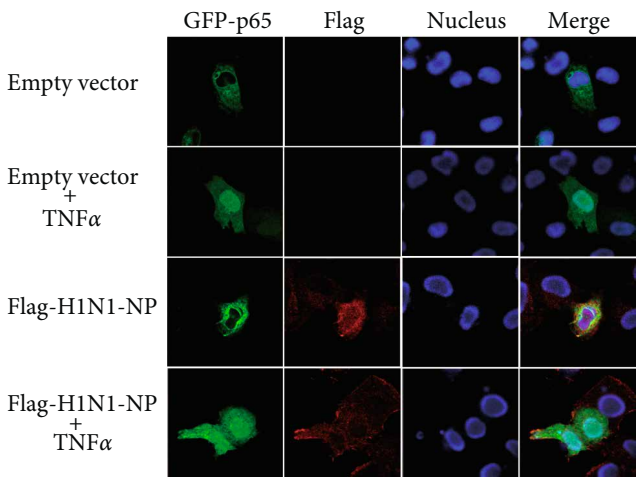

(h)

FIGURE 1: H5N1 NP and H1N1 NP have different impacts on TNF- $\alpha$-induced NF- $\kappa$ B activation. 293 T cells in 24 -well plates were cotransfected with $125 \mathrm{ng}$ pNF- $\kappa \mathrm{B}-\mathrm{luc}, 25 \mathrm{ng}$ pRL-TK and indicated amount of H5N1 NP (a) and H1N1 NP (b) expression plasmid, or empty vector for $24 \mathrm{~h}$. Cells were then mock-treated or treated with TNF- $\alpha(10 \mathrm{ng} / \mathrm{ml})$ for $6 \mathrm{~h}$. Reporter activity was determined by dual-luciferase reporter assays. The resultant ratios were normalized to the fold-change value by that of TNF- $\alpha$-untreated cells cotransfected with empty vector, pNF$\kappa \mathrm{B}$-luc and pRL-TK. Data shown represent three independent experiments, with each determination performed in duplicate (mean \pm SD of fold change). Asterisks indicate significant differences between groups ( ${ }^{* *} p<0.05$, Student's $t$-test). $293 \mathrm{~T}$ cells transfected with empty vector, H5N1 NP or H1N1 NP-expressing plasmid were stimulated with TNF- $\alpha(20 \mathrm{ng} / \mathrm{ml})$ for indicated durations. Equal amounts of cell lysates were analyzed by immunoblotting with the anti- $\mathrm{I} \kappa \mathrm{B} \alpha$ antibody or the anti-phospho-I $\kappa \mathrm{B} \alpha$ antibody (c-f). HeLa cells were transfected with H5N1 NP, H1N1 NP expression plasmid, or empty vector for $30 \mathrm{~h}$. The cells were then mock-treated or treated with TNF- $\alpha$ (10 ng/ml) for $30 \mathrm{~min}$. HeLa cells were subjected to immunofluorescence staining for detection of p65 subcellular localization by using rabbit anti-p65 and FITC-conjugated secondary Ab (green). H5N1 NP and H1N1 NP expression levels were detected using a mouse anti-Flag tag and Texas Red-conjugated secondary Ab (red). Nuclei were stained by Hoechst 33258 (blue) (g, h). 


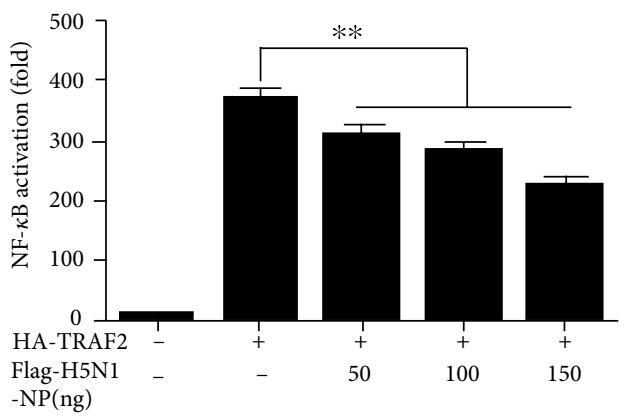

(a)

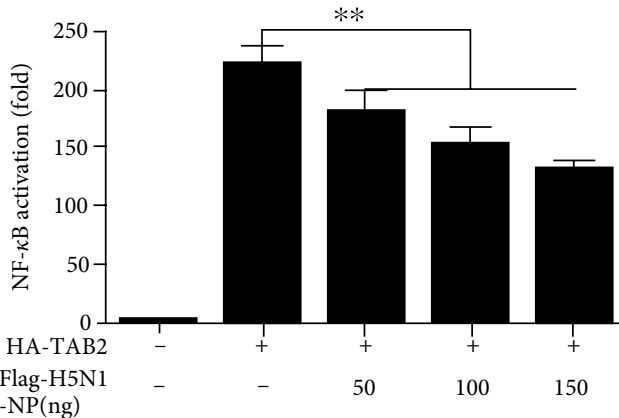

(c)

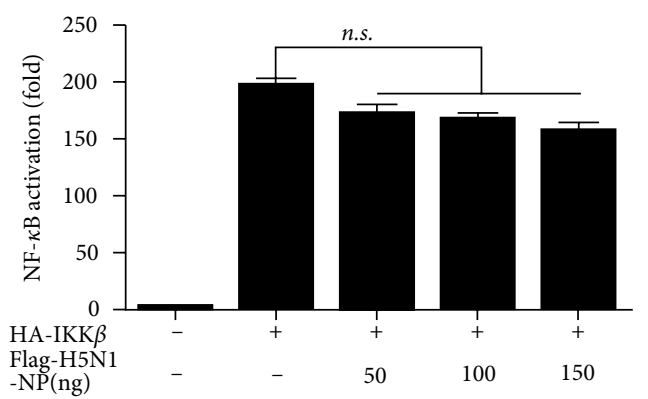

(e)

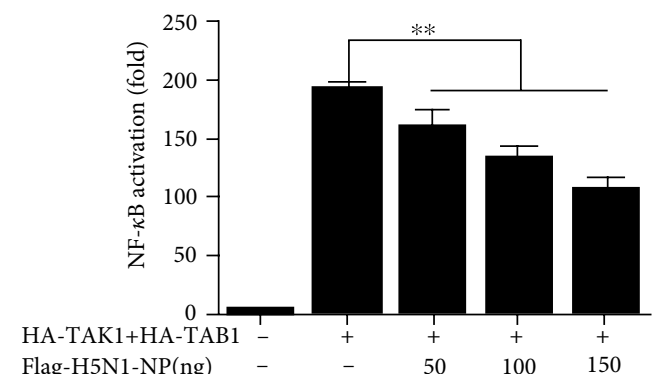

(b)

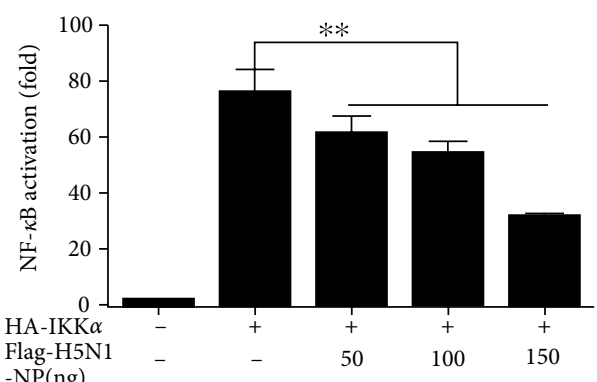

(d)

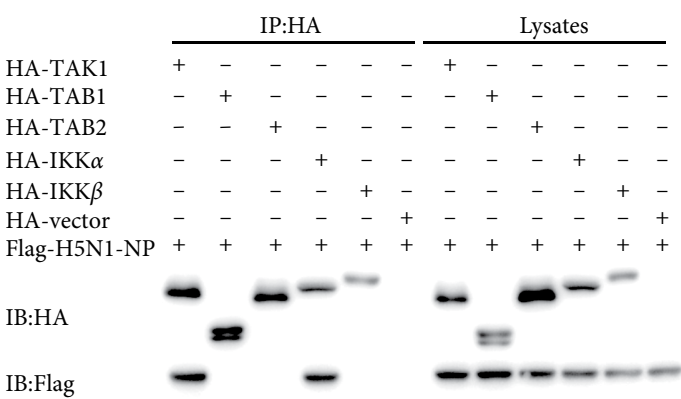

(f)

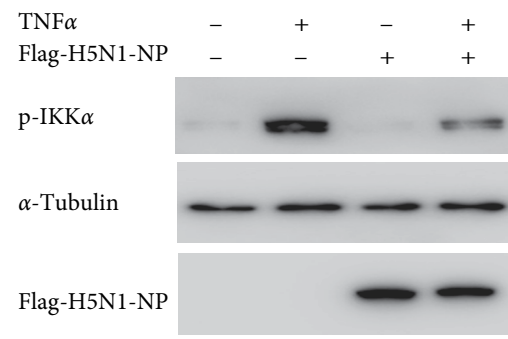

(g)

FIGURE 2: H5N1 NP inhibits the NF- $\kappa \mathrm{B}$ signaling pathway by targeting IKK $\alpha$. $293 \mathrm{~T}$ cells in 24 -well plates were cotransfected with $125 \mathrm{ng}$ pNF- $\kappa$ B-luc, 25 ng pRL-TK and either HA-TRAF2 (a), HA-TAK1+HA-TAB1 (b), HA-TAB2 (c), HA-IKK $\alpha$ (d), HA-IKK $\beta$ (e), together with the indicated amounts of H5N1 NP expression plasmids. Total amounts of transfected DNA were kept equal by adding empty vector. Reporter activity was determined 30-h post-transfection by the dual-luciferase reporter assays. The resultant ratios were normalized to the foldchange value by that of cells cotransfected with empty vectors, pNF- $\kappa$ B-luc and pRL-TK. Data represent at least 3 independent experiments, with each determination performed in duplicate (mean \pm SD of fold-change). Asterisks indicate significant differences between groups $\left({ }^{* *} p<0.05\right.$, Student's $t$-test). 293 T cells were transfected with Flag-H5N1 NP or either HA-TAK1 orSS HA-TAB1 or HA-TAB2 or HA-IKK $\alpha$ or HA-IKK $\beta$ HA-vector expression plasmids for $30 \mathrm{~h}$. All cells were then treated with TNF- $\alpha(10 \mathrm{ng} / \mathrm{ml})$ for $30 \mathrm{~min}$. The cells were lysed and subjected to immunoprecipitation (IP) using the mouse anti-HA tag. IP products and 5\% input samples were analyzed by immunoblotting (f), $293 \mathrm{~T}$ cells transfected with empty vector, H5N1 NP -expressing plasmid were stimulated with TNF- $\alpha(20 \mathrm{ng} / \mathrm{ml})$ for indicated durations. Equal amounts of cell lysates were analyzed by immunoblotting with the anti-phospho-IKK $\alpha$ antibody (g).

The nuclear translocation of NF- $\kappa \mathrm{B}$ is a prerequisite for the promotion of downstream genes [22]. Immunofluorescence also showed that almost all the p65 proteins were retained in the cytoplasm after treatment with TNF- $\alpha$ in the H5N1-NPGFP-transfected cells (Figure 1(g)), while p65 transported from cytoplasm to nucleus in the H1N1-NP-GFP-transfected 


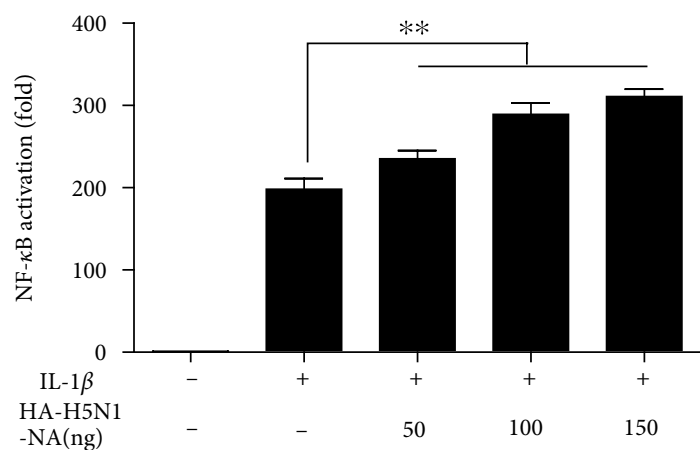

(a)

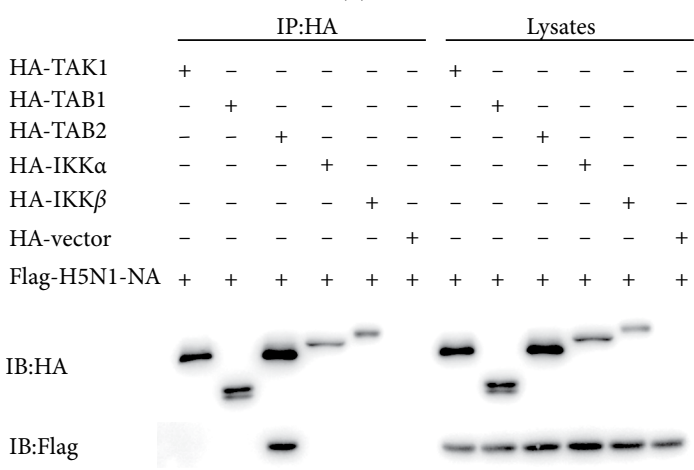

(c)

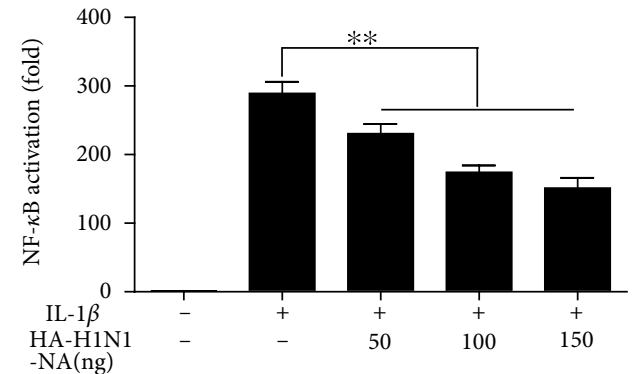

(b)

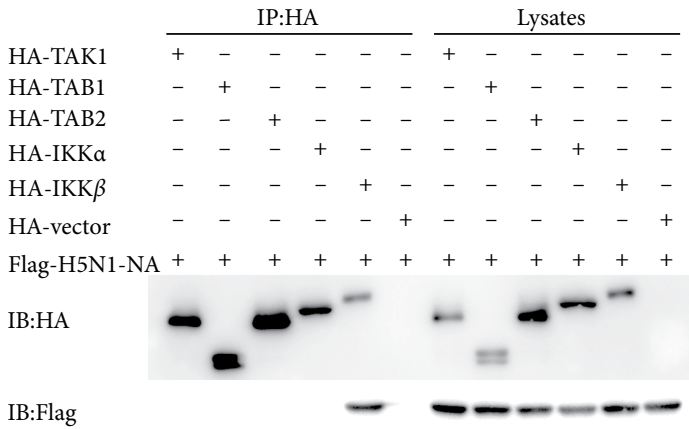

(d)

Figure 3: H5N1 NA and H1N1 NA have different impacts on IL-1 $\beta$-induced NF- $\kappa$ B activation. 293 T cells in 24 -well plates were cotransfected with $125 \mathrm{ng}$ pNF- $\kappa \mathrm{B}-\mathrm{luc}, 25 \mathrm{ng}$ pRL-TK and indicated amount of H5N1 NA (a) and H1N1 NA (b) expression plasmid, or empty vector for $24 \mathrm{~h}$. Cells were then mock-treated or treated with IL- $1 \beta(10 \mathrm{ng} / \mathrm{ml})$ for $6 \mathrm{~h}$. Reporter activity was determined by dual-luciferase reporter assays. The resultant ratios were normalized to the fold-change value by that of IL- $1 \beta$-untreated cells cotransfected with empty vector, pNF- $\kappa \mathrm{B}-$ luc and pRL-TK. Data shown represent three independent experiments, with each determination performed in duplicate (mean \pm SD of fold change). Asterisks indicate significant differences between groups $\left({ }^{* *} p<0.05\right.$, Student's $t$-test). $293 \mathrm{~T}$ cells were transfected with Flag-H5N1 NA (c) or Flag-H1N1 NA (d) or either HA-TAK1 or HA-TAB1 or HA-TAB2 or HA-IKK $\alpha$ or HA-KK $\beta$ or HA-vector expression plasmids for 30 h. All cells were then treated with IL- $1 \beta(10 \mathrm{ng} / \mathrm{ml})$ for $30 \mathrm{~min}$. The cells were lysed and subjected to immunoprecipitation (IP) using the mouse anti-HA tag. IP products and $5 \%$ input samples were analyzed by immunoblotting.

cells (Figure 1(h)). These findings indicated that H5N1 NP and H1N1 NP had different impacts on the TNF- $\alpha$-induced NF- $\kappa$ B activation.

3.2. H5N1 NP Inhibits the NF- $\kappa B$ Signaling Pathway by Targeting IKK $\alpha$. The results above indicated that H5N1 NP had an inhibitory effect on the NF- $\kappa$ B signaling pathway. Next, we intended to investigate which host protein the NP protein targeted on to get this effect. Firstly, we examined the effects of $\mathrm{H} 5 \mathrm{~N} 1 \mathrm{NP}$ protein on the luciferase activity mediated by overexpression of TNF- $\alpha$ signaling transducers along the NF$\kappa \mathrm{B}$ signaling pathway. H5N1 NP protein inhibited TRAF2, TAK1 + TAB1, TAB2, IKK $\alpha$-induced NF- $\kappa$ B activation in a dose-dependent manner (Figures 2(a)-2(d)) and had little effect on the IKK $\beta$-mediated luciferase activity (Figure 2(e)). These results showed that the potential targets of H5N1 NP on the NF- $\kappa \mathrm{B}$ signaling pathway may include the IKK $\alpha$ and the complex of TAK. Results of co-immunoprecipitation showed that H5N1 NP binds to IKK $\alpha$, indicating that there were protein-protein interactions between $\mathrm{H} 5 \mathrm{~N} 1 \mathrm{NP}$ and the TAK1 and IKK $\alpha$ in cells (Figure 2(f)).
The activation of IKK $\alpha$ by phosphorylation is required to the phosphorylation of $I \kappa B$ [23]. We therefore tested whether H5N1 NP played a role in inhibiting the phosphorylation of the IKK $\alpha$. The results showed that H5N1 NP protein may have blocked the TNF- $\alpha$-mediated IKK $\alpha$ phosphorylation (Figure $2(\mathrm{~g}))$.

3.3. H5N1 NA and H1N1 NA Have Different Impacts on the IL-1 $\beta$-Induced NF- $\kappa B$ Activation. Neuraminidase (NA) is an integral membrane glycoprotein and a second major surface antigen of the IAV. During the infection process of IAV, NA cleaves terminal sialic acid from glycoproteins or glycolipids to free virus particles from host cell receptors and facilitate virus spread $[6,24]$.

To study the different impacts of the NA proteins of $\mathrm{H} 5 \mathrm{~N} 1$ and $\mathrm{H} 1 \mathrm{~N} 1$ on the NF- $\kappa \mathrm{B}$ signaling pathways, reporter plasmid pNF- $\kappa$ B-luc and internal control plasmid pRL-TK, together with pH5N1 NA and pH1N1 NA or empty vector, were cotransfected into $293 \mathrm{~T}$ cells. At 24 -h post-transfection, cells were mock-treated or treated with human IL- $1 \beta$ for $6 \mathrm{~h}$. These results showed that the H5N1 NA significantly promoted 
IL- $1 \beta$-stimulated NF- $\kappa$ B promoter activity (Figure $3(\mathrm{a})$ ), while the H1N1 NA had an inhibitory impact on it (Figure 3(b)).

We inferred that the potential targets of the H5N1 NA on the NF- $\kappa \mathrm{B}$ signaling pathway was the complex of TAK (Figure $\mathrm{S} 1$ ), and the potential targets of the H1N1 NA were TAB2 and IKK $\beta$ (Figure S2). Similarly, by implementing co-immunoprecipitation essays, we found that H5N1 NA interacted with TAB2 of the NF- $\kappa$ B signaling pathway (Figure $3(\mathrm{c})$ ), while $\mathrm{H} 1 \mathrm{~N} 1 \mathrm{NA}$ interacted with IKK $\beta$ in the NF- $\kappa \mathrm{B}$ signaling pathway (Figure 3(d)). Based on these results, we conclude that H5N1 NA and H1N1 NA had different impacts on the IL- $1 \beta$ induced NF- $\kappa \mathrm{B}$ activation.

\section{Discussion}

$\mathrm{NF}-\kappa \mathrm{B}$ signaling pathway is widely found in almost all animal cells and plays a key role in the innate immune defense of host against pathogenic microorganisms invaded [25]. Once being invaded by viruses, the host manipulates the NF- $\kappa \mathrm{B}$ signaling pathway to clear them. To survive, microbial pathogens have evolved strategies to modulate the NF- $\kappa \mathrm{B}$ signaling pathway, which is an important pathogenic mechanism to evade innate immunity and promote replication.

In the process of influenza virus infecting the host, viral proteins or other pathogenic factors will interact with host proteins and signaling pathways. Previous research found that the IAV NS1 protein specifically inhibits IKK-mediated NF- $\kappa$ B activation and production of the NF- $\kappa \mathrm{B}$ induced antiviral genes [19]. One report showed that PB1-F2 binds to IKK $\beta$ and impairs DNA-binding of NF- $\kappa \mathrm{B}$ [26]. In contrast, another study reports on an NF- $\kappa$ B intensifying activity of PB1-F2 [27]. In our study, we focused on the regulation of NF- $\kappa \mathrm{B}$ signaling pathway by NP and NA proteins.

Firstly, we found the NP protein of $\mathrm{H} 5 \mathrm{~N} 1$ virus inhibited the transcriptional activation of the TNF- $\alpha$-induced NF- $\kappa \mathrm{B}$ signaling pathway (A/goose/Jilin/hb/2003 (H5N1), Figure 1(a)) [28]. In the absence of stimuli, NF- $\kappa \mathrm{B}$ dimers are retained in the cytosol through association with an inhibitor of $\kappa \mathrm{B}$ activity, termed $\mathrm{I} \kappa \mathrm{B}[29]$. Stimulus-induced degradation of $\mathrm{I} \kappa \mathrm{B}$ molecules leads to nuclear accumulation of $\mathrm{p} 65$, which is the basis of NF- $\kappa \mathrm{B}$ activation. In our study, H5N1 NP protein abolished I $\kappa \mathrm{kB} \alpha$ phosphorylation and degradation of $\mathrm{I} \kappa \mathrm{B} \alpha$, which makes NF- $\kappa$ B dimers immobilized in the cytoplasm. The results of immunofluorescence experiments in Figure 1 verified that nuclear factors were still in the cytoplasm. Our study reveals a potential mechanism by which $\mathrm{H} 5 \mathrm{~N} 1$ virus evades human innate immune responses.

Although the H5N1 NP inhibited TNF-mediated NF- $\kappa \mathrm{B}$ activation and the $\mathrm{H} 5 \mathrm{~N} 1 \mathrm{NA}$ activated NF- $\kappa \mathrm{B}$ downstream of IL- $1 \beta$ in this paper, it has been reported that the overall NF- $\kappa \mathrm{B}$ activation status upon infection by the $\mathrm{H} 5 \mathrm{~N} 1$ subtype is activated. We speculated that the inhibitory effects of NP protein on TNF- $\alpha$-mediated NF- $\kappa$ B activation can inhibit the antiviral immune response of the hosts in the early stage of invasion and promote the massive replication of the virus, while the NA protein promotes the IL- $1 \beta$-mediated NF- $\kappa$ B activation, which may promote apoptosis of host cells. Both of the two facts of the two proteins may benefit the spread of the virus.
However, in our experiment with H1N1 NP as the experimental object, we found that H1N1 NP hardly affected the NF- $\kappa$ B signaling pathway (A/Beijing/501/2009 (H1N1), Figure 1(b)). We did not observe any significant change in the degradation and phosphorylation of $\mathrm{I} \kappa \mathrm{B} \alpha$ protein. Nuclear translocation of p65 was also not affected by H1N1 NP. We speculate that the different effects between the two viral NP proteins and the NF- $\kappa \mathrm{B}$ signaling pathway lead to differssent pathogenicity to some extent, but a more detailed mechanism needs further investigation.

NA is one of the major antigenic targets of the humoral immune response to IAV and the target of the antiviral drugs oseltamivir and zanamivir [30]. Our studies on the neuraminidase protein showed that the NA protein of $\mathrm{H} 5 \mathrm{~N} 1$ virus promotes the transcriptional activation of IL- $1 \beta$-induced $\mathrm{NF}-\kappa \mathrm{B}$, while the NA protein of $\mathrm{H} 1 \mathrm{~N} 1$ influenza virus inhibits the corresponding activation.

Considering the cells we used in the experiments, it is true that $293 \mathrm{~T}$ and HeLa cells are not the main target organ of influenza virus and do not support its productive infections; however, here in this study, we tried to evaluate the possible host target of the NP and NA proteins in the NF- $\kappa \mathrm{B}$ signaling pathway, a process that happened after virus infection. Nevertheless, A549 is a more suitable cell model for studying influenza virus, which we will use in our future study.

The comparison of the above two groups of results indicates that the interaction between influenza virus proteins and host signaling pathway proteins has subtype-specific characteristics, which can respond to the specific pathogenic mechanism of influenza virus of different subtypes. The viral proteins employed to target at these conserved pathways are different for different subtypes of IAVs, suggesting more subtype-specific pathogenic mechanisms need to be revealed in the future research work.

\section{Conclusion}

Our study shows that different proteins of varied influenza viruses will produce distinct interaction effects with host NF- $\kappa \mathrm{B}$ signaling pathway. The interaction between influenza viral proteins and host proteins is subtype-specific. This specificity may due to the specific pathogenic mechanisms of different subtypes of influenza viruses. Our discovery may suggest a new way of thinking about flu treatment and provide potential avenues to study pathogenesis of avian influenza.

\section{Conflicts of Interest}

The authors declare that there is no conflicts of interest.

\section{Author's Contributions}

Long Liang, Hongguang Ren and Junjie Yue conceived and supervised the study. Ting Song and Long Liang designed the experiments. Yujie Wang, Ting Song and Kaiwu Li performed the experiments. Hongguang Ren and Yuan Jin analyzed the data. Hongguang Ren and Yujie Wang wrote the manuscript. Yujie Wang and Ting Song contributed equally to this work. 


\section{Acknowledgments}

We thank Prof. Hui Zhong (Beijing Institute of Biotechnology) for helpful discussion and suggestion. This work was supported by the National Natural Science Foundation of China (31800136), Beijing Nova Program (Z171100001117120) and the Independent Research Project from State Key Laboratory of Pathogen and Biosecurity (SKLPBS1807).

\section{Supplementary Materials}

The Supplementary Materials file contains two figures illustrating the potential targets of the NA proteins of the $\mathrm{H} 5 \mathrm{~N} 1$ (Figure S1) and H1N1 (Figure S2) on the NF- $\kappa \mathrm{B}$ signaling pathway. (Supplementary Materials)

\section{References}

[1] M. I. Nelson and A. L. Vincent, "Reverse zoonosis of influenza to swine: new perspectives on the human-animal interface," Trends in microbiology, vol. 23, no. 3, pp. 142-153, 2015.

[2] M. Gerber, C. Isel, V. Moules, and R. Marquet, "Selective packaging of the influenza a genome and consequences for genetic reassortment," Trends in Microbiology, vol. 22, no. 8, pp. 446-455, 2014.

[3] J. J. Skehel and A. J. Hay, "Influenza virus transcription," Journal of General Virology, vol. 39, no. 1, pp. 1-8, 1978.

[4] R. A. Lamb and R. M. Krug, Fields Virology, Lippincott-Raven, Philadelphia, 4th edition, 2001.

[5] S. Tong, X. Zhu, Y. Li et al., "New world bats harbor diverse influenza A viruses," PLoS Pathogens, vol. 9, no. 10, p. e1003657, 2013.

[6] R. G. Webster, W. J. Bean, O. T. Gorman, T. M. Chambers, and Y. Kawaoka, "Evolution and ecology of influenza A viruses," Microbiological Reviews, vol. 56, no. 1, pp. 152-179, 1992.

[7] T. Horimoto and Y. Kawaoka, "Influenza: lessons from past pandemics, warnings from current incidents," Nature Reviews Microbiology, vol. 3, no. 8, pp. 591-600, 2005.

[8] J. Zhou, W. Sun, J. Wang et al., "Characterization of the H5N1 highly pathogenic avian influenza virus derived from wild pikas in China," Journal of Virology, vol. 83, no. 17, pp. 8957-8964, 2009.

[9] K. B. Westgeest, C. A. Russell, X. Lin et al., "Garcia-genomewide analysis of reassortment and evolution of human influenza A(H3N2) viruses circulating between 1968 and 2011," Journal of Virology, vol. 88, no. 5, pp. 2844-2857, 2014.

[10] J. W. Zheng, B. Meng, and X. Y. Li, "NF- $\kappa$ B/P65 signaling pathway: a potential therapeutic target in postoperative cognitive dysfunction after sevoflurane anesthesia," European Review for Medical and Pharmacological Sciences, vol. 21, no. 2, pp. 394-407, 2017.

[11] S.-C. Sun, "The non-canonical NF- $\kappa$ B pathway in immunity and inflammation," Nature Reviews Immunology, vol. 17, no. 9, pp. 545-558, 2017.

[12] S. Vallabhapurapu and M. Karin, "Regulation and function of NF- $\kappa \mathrm{B}$ transcription factors in the immune system," Annual Review of Immunology, vol. 27, no. 1, pp. 693-733, 2009.

[13] M. M. Rahman and G. McFadden, "Modulation of NF- $\kappa$ B signalling by microbial pathogens," Nature Reviews Immuno$\log y$, vol. 9, no. 4, pp. 291-306, 2011.
[14] Q. Liu, Z. Zhang, Z. Zheng et al., "Human bocavirus NS1 and NS1-70 proteins inhibit TNF-alpha-mediated activation of NF- $\kappa \mathrm{B}$ by targeting p65," Scientific Reports, vol. 6, no. 1, p. 28481, 2016.

[15] S. Franz, P. Rennert, M. Woznik et al., "Mumps virus SH protein inhibits NF- $\kappa \mathrm{B}$ activation by interacting with tumor necrosis factor receptor 1, interleukin-1 receptor 1, and toll-like receptor 3 complexes," Journal of Virology, vol. 91, no. 18, 2017.

[16] G. Brady, D. A. Haas, P. J. Farrell, A. Pichlmair, and A. G. Bowie, "Molluscum contagiosum virus protein Mc005 inhibits NF- $\kappa \mathrm{B}$ activation by targeting NEMO-regulated I $\kappa$ B kinase activation," Journal of Virology, vol. 91, no. 15, 2017.

[17] M. M. Brinkmann, M. Pietrek, O. Dittrich-Breiholz, M. Kracht, and T. F. Schulz, "Modulation of host gene expression by the K15 protein of Kaposi's sarcoma-associated herpesvirus," Journal of Virology, vol. 81, no. 1, pp. 42-58, 2007.

[18] F. E. Dufrasne, M. Lucchetti, A. Martin et al., "Modulation of the NF- $\kappa$ B signaling pathway by the HIV-2 envelope glycoprotein and its incomplete BST-2 antagonism," Virology, vol. 513, pp. 11-16, 2018.

[19] S. Gao, L. Song, J. Li et al., "Influenza A virus-encoded NS1 virulence factor protein inhibits innate immune response by targeting IKK," Cellular Microbiology, vol. 14, no. 12, pp. 1849-1866, 2012.

[20] L. Turrell, J. W. Lyall, L. S. Tiley, E. Fodor, and F. T. Vreede, “The role and assembly mechanism of nucleoprotein in influenza A virus ribonucleoprotein complexes," Nature Communications, vol. 4, no. 1591, 2013.

[21] A. Denk, M. Goebeler, S. Schmid et al., "Activation of NF- $\kappa$ $\mathrm{B}$ via the I $\kappa$ B kinase complex is both essential and sufficient for proinflammatory gene expression in primary endothelial cells," Journal of Biological Chemistry, vol. 276, no. 30, pp. 28451-28458, 2001.

[22] T. Kobayashi and R. Kageyama, "Dynamic advances in NF- $\kappa$ B signaling analysis," Science Signaling, vol. 2, no. 81, p. pe47, 2009.

[23] M. L. Schmitz, M. Kracht, and V. V. Saul, "The intricate interplay between RNA viruses and NF- $\kappa \mathrm{B}$," Biochimica et Biophysica Acta(BBA)-Molecular cellResearch, vol. 1843, no. 11, pp. 27542764, 2014.

[24] V. N. Petrova and C. A. Russell, "The evolution of seasonal influenza viruses," Nature Reviews Microbiology, vol. 16, no. 1, pp. 47-60, 2018.

[25] A. Oeckinghaus and S. Ghosh, "The NF- $\kappa$ B family of transcription factors and its regulation," Cold Spring Harbor Perspectives in Biology, vol. 1, no. 4, p. a000034, 2009.

[26] A. L. Reis and J. W. McCauley, “The influenza virus protein PB1-F2 interacts with IKKbeta and modulates NF- $\kappa \mathrm{B}$ signalling," PLoS One, vol. 8, no. 5, p. e63852, 2013.

[27] R. Le Goffic, O. Leymarie, C. Chevalier et al., “Transcriptomic analysis of host immune and cell death responses associated with the influenza A virus PB1-F2 protein," PLoS Pathog, vol. 7, no. 8, p. e1002202, 2011.

[28] E. O'Dea and A. Hoffmann, "NF- $\kappa$ B signaling," Wiley Interdisciplinary Reviews: Systems Biology and Medicine, vol. 1, no. 1, pp. 107-115, 2009.

[29] V. Tergaonkar, R. G. Correa, M. Ikawa, and I. M. Verma, "Distinct roles of $\mathrm{I} \kappa \mathrm{B}$ proteins in regulating constitutive NF$\kappa$ B activity," Nature Cell Biology, vol. 7, no. 9, pp. 921-923, 2005.

[30] J. K. Taubenberger and J. C. Kash, "Influenza virus evolution, host adaptation, and pandemic formation," Cell Host \& Microbe, vol. 7, no. 6, pp. 440-451, 2010. 


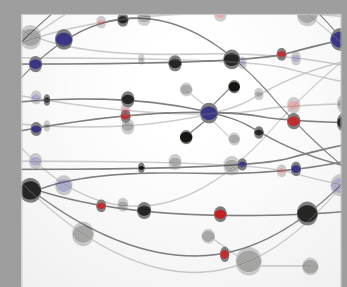

The Scientific World Journal
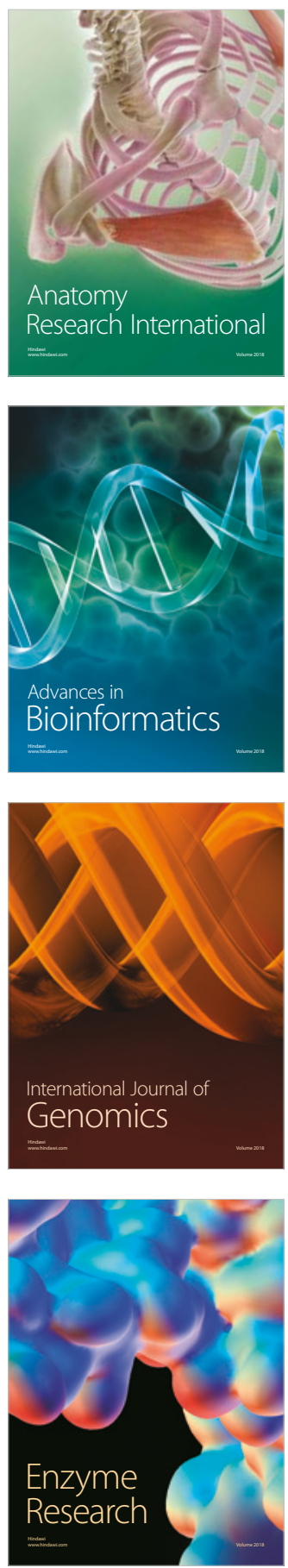
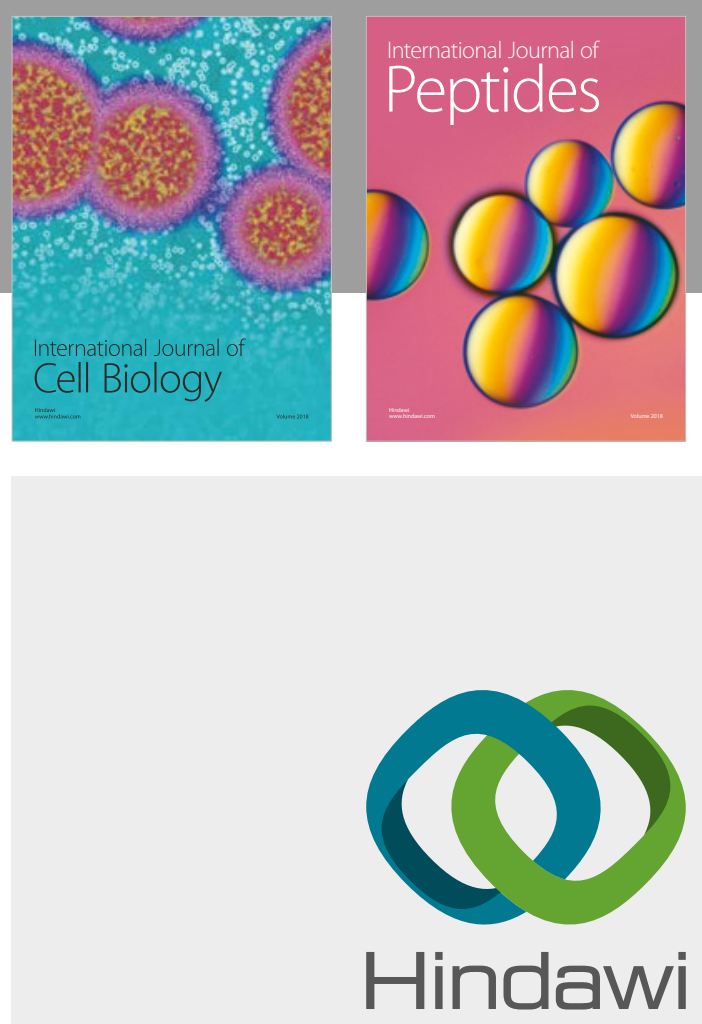

Submit your manuscripts at

www.hindawi.com
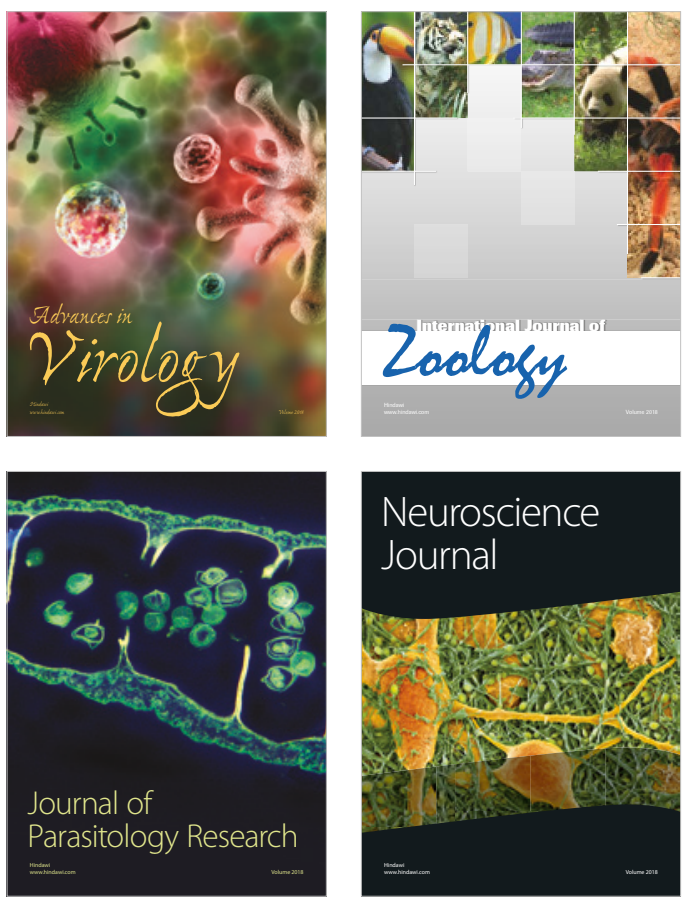
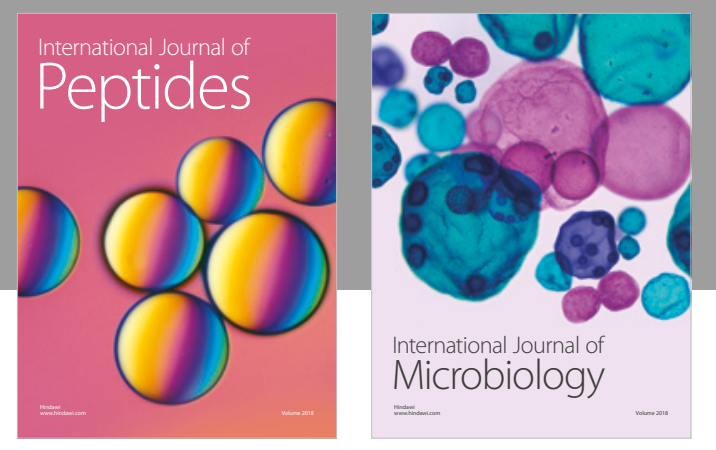

nternational Journal of Microbiology
Journal of
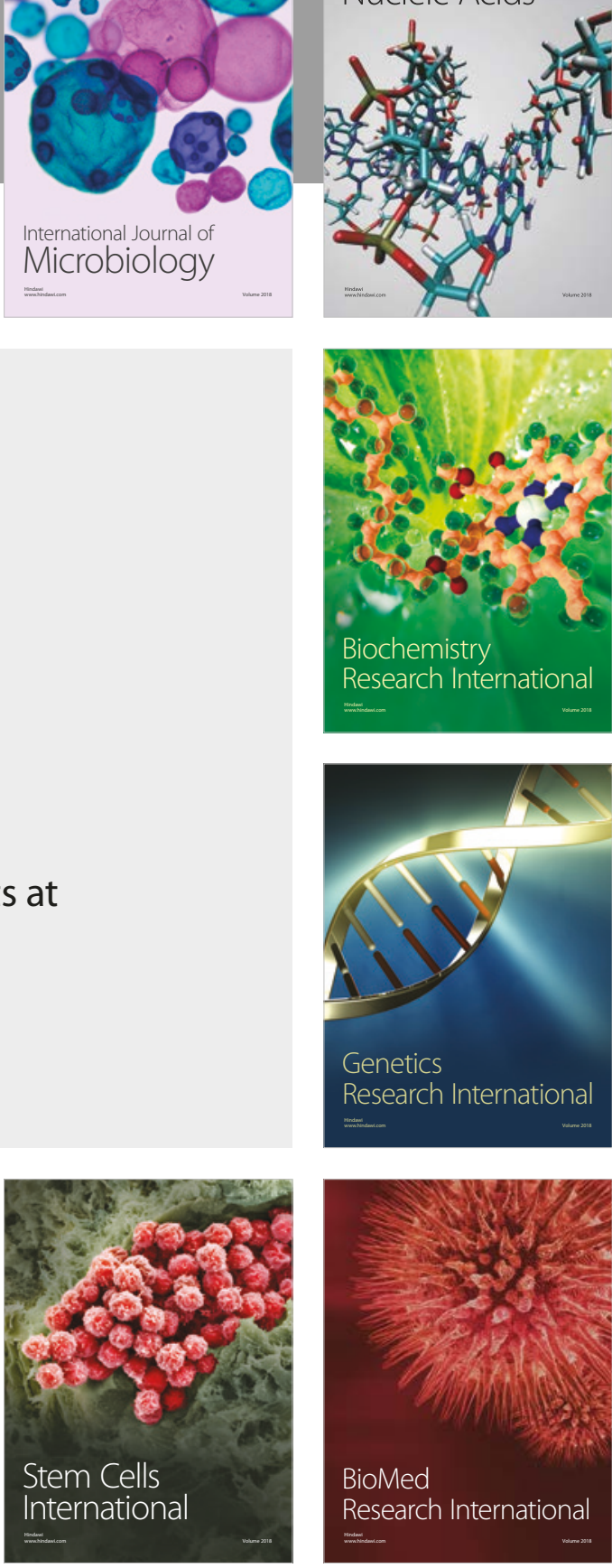
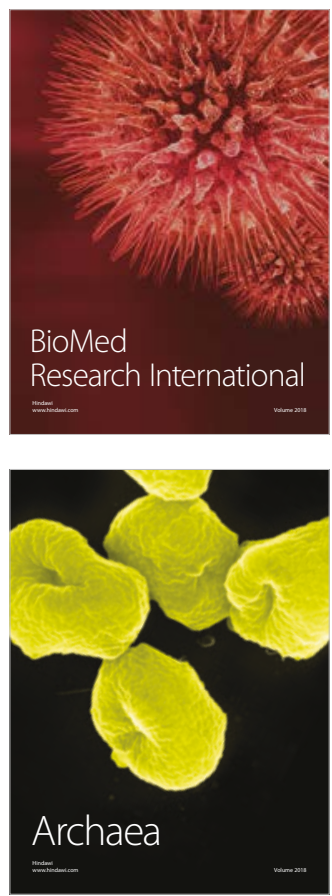